Tohoku J. exp. Med., 1969, 99, 105-106

Short Report

\title{
Frequency-force Relationship in the Blood Perfused Papillary Muscle of the Dog
}

\author{
Masao Endoh and Koroku Hashimoto \\ Department of Pharmacology (Prof. K. Hashimoto), \\ Tohoku University School of Medicine, Sendai
}

\begin{abstract}
The anterior papillary musele of the canine right ventricle was perfused at a constant pressure of $100 \mathrm{~mm} \mathrm{Hg}$ with the blood from the donor dog by a crosscirculation technique. Temperature was kept constant at 38 to $39^{\circ} \mathrm{C}$. Isometric tension was measured by a force displacement transducer. The muscle was electrically stimulated at the voltage approximately twice the threshold $(0.5$ to 1.5 volts), $5 \mathrm{msec}$ and at variable frequencies from 36 to $360 \mathrm{~min}$, because the muscle contracted spontaneously at a rate of $20 \pm 3$ beats/min (mean \pm s.e.; $\mathbf{n}=\mathbf{1 0}$ ). Contractile force was markedly increased by raising the stimulation frequency. The rate of spontaneous contraction, stimulation threshold, and frequency-force relationship were not significantly changed in the course of experiments of 10 to 20 hours.

None of atropine, $\beta$-adrenergic blocking agent and tetrodotoxin modified the frequency-force relationship.

These results demonstrate that the frequency-force relationship is a characteristic property of the ventricular muscle itself and there is no participation of the autonomic nerve stimulation.
\end{abstract}

The cat papillary muscle preparation has been widely used for the studies on physiological and pharmacological properties of myocardium, since Cattell and Gold ${ }^{1}$ used it in the study of digitalis glucosides. However, oxygen supply is restricted because of limited diffusion from the surface, and therefore the frequencyforce relationship, one of basic characters of myocardium, may be modified by hypoxia when the muscle is stimulated above a given range of frequency (Blinks and Koch-Weser ${ }^{2}$ ). As a matter of fact, contractile force was not influenced significantly by stimulation frequency under condition of an intact circulation $\left(\right.$ Cotten $\left.^{3}\right)$. Then the authors performed the perfusion of the canine papillary muscle by a cross-circulation technique in order to reinvestigate the frequencyforce relationship.

Twenty-seven mongrel dogs, weighing 7 to $11 \mathrm{~kg}$, were anesthetized with ether. The heart was excised quickly and plunged into Tyrode's solution at 3 to $6^{\circ} \mathrm{C}$, equilibrated with $5 \% \mathrm{CO}_{2}$ in $\mathrm{O}_{2}$. The right side of the interventricular septum was exposed and the

Received for publication, July 14, 1969. 
anterior papillary muscle was dissected with anterior septal artery. The papillary muscle was perfused through the papillary muscle arteries with the blood from the heparinized donor dog by the aid of a Sigma motor pump. Isometric tension was measured by a force displacement transducer and recorded on an ink-writing oscillograph (Nihon Kohden WI-130). The muscle contracting with spontaneous rhythm of $20 \pm 3$ beats $/ \min (n=10)$ was electrically driven $(0.5$ to 1.5 volts, $5 \mathrm{msec}$ and variable frequencies from 36 to 360 beats $/ \mathrm{min}$ ). Threshold voltage for electrical stimulation was 0.2 to 0.7 volts. The frequency of automatic rhythm and the threshold voltage were almost the same throughout the experiment.

Stepwise rise of stimulation frequency caused the augmentation of the contractile force, as typically shown in Fig. 1. Slight alternation of tension developed at 210 beats/min, which became marked when the frequency was raised above $240 \mathrm{beats} / \mathrm{min}$. The frequency-force relationship was almost constant over 10 hours of experimental schedule. $100 \mu \mathrm{g}$ of atropine blocked completely the negative inotropic effect of $10 \mu \mathrm{g}$ of $\mathrm{ACh}$, and $\beta$-adrenergic blocking agent $(1.0 \mu \mathrm{g}$ of 1-(o-allylphenoxy)-3-isopropylamino-2-propanol (H56/28)) blocked entirely the positive inotropic effect of $0.01 \mu \mathrm{g}$ of norepinephrine (Fig. 1.), but none of $100 \mu \mathrm{g}$ of atropine, $\beta$-adrenergic blocking agent and tetrodotoxin affected the frequencyforce relationship. Then the possibility of the participation of autonomic nerve fibers was excluded. Thus the authors conclude that the frequency-force relationship is a characteristic property of the ventricular muscle itself under condition of intact coronary circulation.

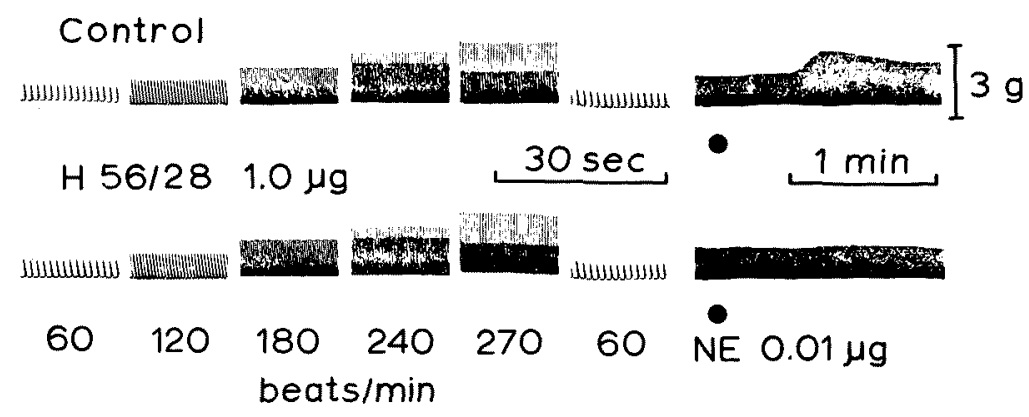

Fig. 1. Potentiation of contractile force of the blood perfused canine papillary muscle by increasing frequency of electrical stimulation, and absence of effect of $1.0 \mu \mathrm{g}$ of $\mathrm{H} 56 / 28$, a $\beta$-adrenergic blocking agent, on the frequency-force relationship. NE: norepinephrine. Numbers below the lower tracings indicate beats per minute.

\section{References}

1) Cattell, $\mathrm{McK}$. \& Gold, H. The influence of digitalis glucosides on the force of contraction of mammalian cardiac muscle. J. Pharmacol. exp. Ther., 1938, 62, 116125.

2) Blinks, J.R. \& Koch-Weser, J. Physical factors in the analysis of the actions of drugs on myocardial contractility. Pharmacol. Rev., 1963, 15, 531-599.

3) Cotten, M. DeV. Circulatory changes affecting measurement of heart force in situ with strain gauge arches. Amer. J. Physiol., 1953, 174, 365-370. 